\title{
The clinicopathological and prognostic value of HSP27 in hepatocellular carcinoma: a systematic review and meta-analysis
}

This article was published in the following Dove Press journal:

OncoTargets and Therapy

\section{Chaojie Liang* \\ Yingchen $\mathrm{Xu}^{*}$ \\ Hua $\mathrm{Ge}$ \\ Guangming Li \\ jixiang Wu}

Department of General Surgery, Beijing Tongren Hospital, Capital Medical University, Beijing, China

*These authors contributed equally to this work
Correspondence: Jixiang Wu;

Guangming $\mathrm{Li}$

Department of General Surgery, Beijing

Tongren Hospital, Capital Medical

University, No 2, Chongwenmennei

Street, Dongcheng, Beijing, 100730, China

Tel +86 I 380 I0। 5। I8;

+86 I 350 II 2244

Email trwujixiang2016@I26.com;

liguangming2016@126.com
Background: In the recent past, there is increasing evidence demonstrating that HSP27 plays a key role in tumor progression. However, the relationship between HSP27 expression and the clinicopathological features of hepatocellular carcinoma (HCC), as well as its prognostic value in HCC patients remain controversial. Accordingly, we conducted a meta-analysis to assess the correlation between HSP27 expression and HCC, and determine the prognostic value of HSP27 in HCC.

Methods: The data included clinicopathological features and survival information extracted from the published literature in the databases PubMed, EMBASE, Cochrane Library, Web of Science, CNKI, and Wan Fang. The pooled odds ratios and hazard ratios with 95\% CIs were calculated using Forest plot analysis.

Results: The meta-analysis results indicated that the positive HSP27 expression was significantly correlated with $\mathrm{HCC}$ incidence, tumor differentiation, and $\alpha$-fetoprotein level in patients with HCC. However, the expression of HSP27 was not associated with metastasis, hepatitis B virus surface antigen, gender, tumor size, TNM stage, and vascular invasion. Additionally, HSP27 expression indicated a poor overall survival rate, but it was not related to disease-free survival rate.

Conclusion: This meta-analysis revealed that HSP27 may play a key role in the development of HCC and could be a reliable biomarker for the prognosis of patients with HCC. However, additional high-quality research is needed to support the results.

Keywords: HCC, heat shock protein 27 , meta-analysis

\section{Introduction}

Hepatocellular carcinoma (HCC) is one of the most common malignant tumors worldwide. The annual number of new cases is about 748,300, the number of deaths is 695,900 , and nearly half of the new cases and deaths occur in China. ${ }^{1}$ In recent years, with the development of surgical techniques, the prognosis of patients with HCC has improved. However, the clinical manifestations of HCC are not obvious; thus, its early diagnosis is difficult. Moreover, there is still a lack of specific markers for the diagnosis of HCC, and when HCC is diagnosed, it is frequently in late stage. Consequently, the rate of overall survival of patients with $\mathrm{HCC}$ is still poor. ${ }^{2,3}$ As a result, the search for reliable biomarkers to diagnose $\mathrm{HCC}$ and predict the survival rate of $\mathrm{HCC}$ patients has become a hot research topic in recent years. ${ }^{4}$ Heat shock proteins (HSPs) are a family of conserved proteins produced by cells in response to stressful conditions. They play key roles in various cellular processes, such as maintaining cell homeostasis, apoptosis, invasion, cell signal transduction, and cellular response, and are closely related to the 
development of tumors. ${ }^{5}$ In recent years, studies have found that the abnormal expression of HSPs is closely associated with the incidence and development of $\mathrm{HCC}$, and can be used as one of the diagnosis and prognosis indicators. ${ }^{6}$

HSP27 is an important member of the HSP family, which plays a key role in the occurrence and development of tumors. ${ }^{7}$ HSP27 has been found to be overexpressed in various cancers, including esophageal cancer, ${ }^{8}$ gastric cancer, ${ }^{9}$ colon cancer, ${ }^{10}$ prostate cancer, ${ }^{11}$ breast cancer, ${ }^{12}$ lung cancer, ${ }^{13,14}$ and HCC. ${ }^{15,16}$ In addition, some studies have shown that HSP27 expression was related to the clinicopathological features and prognosis of the tumors. However, the relationship between HSP27 expression and the clinicopathological features of HCC, as well as its prognostic value in patients with $\mathrm{HCC}$ remains controversial. King et $\mathrm{a}{ }^{17}$ determined that the expression of HSP27 was associated with tumor differentiation and poor prognosis, but they found no association with other clinicopathological features. Also, Harimoto et $\mathrm{al}^{18}$ found that the expression of HSP27 was not correlated with vascular invasion, metastasis, tumor differentiation, and other clinical features, and in addition, HSP27 expression was not related to the overall survival and disease-free survival in hepatitis $\mathrm{C}$ virus-positive HCC patients. Moreover, Zhang et $\mathrm{al}^{19}$ found that the expression of HSP27 predicted a poor overall survival and short disease-free survival time. Accordingly, we conducted a meta-analysis to determine the clinicopathological and prognostic value of HSP27 in patients with HCC.

\section{Methods}

\section{Identification and eligibility of relevant studies}

The PubMed, Cochrane Library, Web of Science, EMBASE, Chinese CNKI, and Wan Fang databases were searched to identify studies that evaluate the clinicopathological characteristics and prognostic value of HSP27 expression in HCC patients using immunohistochemistry (IHC) analysis. The search ended on September 1, 2017. Search words were "heat shock protein 27", "HSP27" and "liver cancer", "hepatic carcinoma", "hepatocellular carcinoma", "cancer of the liver". The reference list of the included studies was also checked to find other qualified studies.

The studies should meet the following inclusion criteria: 1) patients in the study should be clearly diagnosed with HCC; 2) the study is published in Chinese or English, and the full text is available; 3) the expression of HSP27 was measured by IHC analysis; 4) the article should be a case-control study and assess the relationship between HSP27 expression and the $\mathrm{HCC}$ clinicopathological features or prognosis, and the study should include at least one primary outcome of interest; and 5) repeat publications were excluded.

\section{Data extraction}

Two reviewers (Chaojie Liang and Hua Ge) independently screened all the articles according to the inclusion criteria. The extracted data included the first author's name, year of publication, sample size, country/region, antibody company, antibody concentration and clinicopathological parameters (HSP27 expression, gender, hepatitis B virus surface antigen [HbsAg], $\alpha$-fetoprotein [AFP], tumor size, metastasis, vascular invasion, tumor differentiation, and TNM stage) and hazard ratios (HRs) with 95\% CI for overall survival and disease-free survival. Disagreements were resolved by re-extraction or third-party adjudication.

\section{Quality assessment}

The quality of each of the included studies was assessed using the Newcastle-Ottawa Scale (NOS) criteria, and studies with NOS score of $>6$ were regarded as good quality, while $<6$ were considered as poor quality.

\section{Statistical analysis}

The STATA 14.2 software was used for statistical analyses. The association between HSP27 expression and the clinicopathological features (gender [male vs female], AFP [positive: negative ratio], HbsAg [yes vs no], tumor size [ $>5 \mathrm{~cm}$ vs $\leq 5 \mathrm{~cm}$ ], metastasis [yes vs no], vascular invasion [yes vs no], tumor differentiation level [low vs high or moderate], and TNM stage [I/II vs III/IV] was evaluated by pooled odds ratios [ORs] with 95\% CIs), and the differential expression of HSP27 between cancer tissues and control tissues was also evaluated. The software Engauge Digitizer 10.0 was used to extract the survival data from Kaplan-Meier curves in the articles. When the 95\% CI did not overlap 1, it was considered to be statistically significant. The heterogeneity between the studies was evaluated by the $I^{2}$ test. The fixed effects model was chosen when there was no significant heterogeneity $\left(I^{2}<50 \%\right.$, P-Het $\left.<0.1\right)$. When the heterogeneity was significant, the random effects model was used. Potential causes of statistical heterogeneity were analyzed by subgroup analysis. Publication bias was examined by the Begg's funnel plot test and inverted funnel plots.

\section{Results \\ Characteristics of studies}

A total of 598 relevant articles were identified by searching the PubMed, Cochrane Library, Web of Science, EMBASE, Chinese CNKI, and Wan Fang databases, as illustrated in 


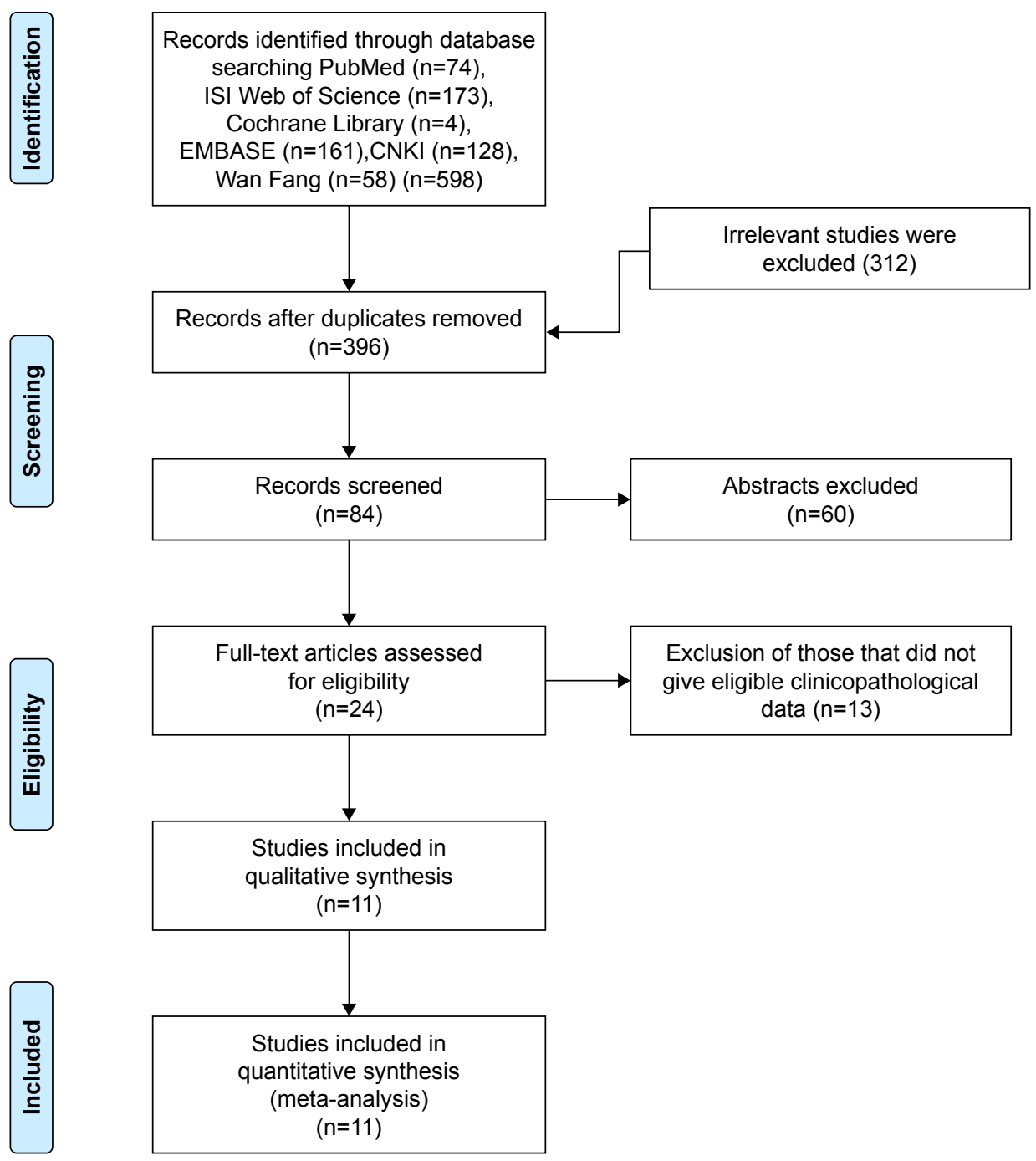

Figure I Flowchart of study selection process.

Figure 1, which shows the details of the selection process. Ultimately, 11 eligible articles were included in this metaanalysis. ${ }^{15-25}$ As shown in Table 1, these studies were published from 2000 to 2017, and included a total of $876 \mathrm{HCC}$ patients. The sample size ranged from 34 to 194 patients, with 6 of studies including $>60$ patients and 5 including $\leq 60$ patients. Eight of the studies evaluated patients from China, 2 from Japan, and 1 from Korea. All these studies scored $\geq 6$ in methodological assessment, which implied that they were of high quality.

\section{The meta-analysis about the relationship between HSP27 expression and clinicopathological features in patients with $\mathrm{HCC}$}

The correlation between HSP27 expression and the clinicopathological features of HCC was assessed in this meta-analysis, and the results are shown in Table 2. Five studies, including a total of 237 patients were used to evaluate the differential expression of HSP27 in HCC and normal tissues. The results revealed that the expression of HSP27 in HCC was significantly higher than that in normal tissue $(\mathrm{OR}=7,95 \%$ $\mathrm{CI}=2.35-20.79, P=0.000$; Figure 2A). The ORs for AFP were reported in 3 studies that included 167 cases. The results of our evaluation of these data indicated that HSP27 expression was associated with AFP expression (OR=3.86, 95\% $\mathrm{CI}=1.11-13.39, P=0.034$; Figure $2 \mathrm{C}$ ). Nine studies including 642 patients showed a significant relationship between HSP27 expression and tumor differentiation $(\mathrm{OR}=3.81$, 95\% CI $=1.79-8.08, P=0.000$; Figure 4B). However, the expression of HSP27 was not significantly associated with any of the following parameters: gender $(\mathrm{OR}=1.13,95 \%$ $\mathrm{CI}=0.72-1.77, P=0.606$; Figure 2$), \mathrm{HBsAg}(\mathrm{OR}=1.72,95 \%$ $\mathrm{CI}=0.65-4.52, P=0.275$; Figure $3 \mathrm{~A})$, tumor size $(\mathrm{OR}=1.19$, 95\% CI $=0.74-1.92, P=0.479$; Figure $3 \mathrm{~B})$, metastasis 
Table I Characteristics of studies included in the meta-analysis

\begin{tabular}{|c|c|c|c|c|c|c|c|c|}
\hline Authors & Year & Country & Kind & $\begin{array}{l}\text { No. of } \\
\text { patients }\end{array}$ & $\begin{array}{l}\text { Antibody } \\
\text { company }\end{array}$ & $\begin{array}{l}\text { Antibody } \\
\text { concentration }\end{array}$ & $\begin{array}{l}\text { Expression } \\
\text { cancer }(+I-) \text {, } \\
\text { control }(+I-)\end{array}$ & $\begin{array}{l}\text { Age }>60(+I-), \\
<60(+I-)\end{array}$ \\
\hline \multirow[t]{2}{*}{ Shen et $\mathrm{al}^{20}$} & 2013 & China & $\mathrm{HCC}$ & 32 & $\begin{array}{l}\text { Fujian Maixin } \\
\text { Technology }\end{array}$ & NA & $18 / 14$ & $10 / 12$ \\
\hline & & & & & & & $3 / 32$ & $8 / 2$ \\
\hline \multirow[t]{2}{*}{ Guo 21} & 2012 & China & $\mathrm{HCC}$ & 68 & $\begin{array}{l}\text { Fujian Maixin } \\
\text { Technology }\end{array}$ & $\mathrm{I}: 200$ & $5 \mathrm{I} / 17$ & NA \\
\hline & & & & & & & $42 / 26$ & \\
\hline \multirow[t]{2}{*}{ Dai et $\mathrm{a}^{22}$} & 2009 & China & $\mathrm{HCC}$ & 45 & NeoMarkers & NA & $30 / 15$ & $21 / 12$ \\
\hline & & & & & & & $0 / 35$ & $9 / 3$ \\
\hline \multirow[t]{2}{*}{ Liang et al ${ }^{15}$} & 2011 & China & $\mathrm{HCC}$ & 34 & NA & NA & $20 / 14$ & NA \\
\hline & & & & & & & $10 / 24$ & \\
\hline \multirow[t]{2}{*}{ Daimei et al ${ }^{16}$} & 2016 & Japan & $\mathrm{HCC}$ & 194 & Streegen & $\mathrm{I}: 400$ & $118 / 76$ & $97 / 53$ \\
\hline & & & & & & & NA & $21 / 23$ \\
\hline \multirow[t]{2}{*}{ Mee et $\mathrm{al}^{24}$} & 2005 & Korea & $\mathrm{HCC}$ & 71 & NeoMarkers & $\mathrm{I}: 50$ & $44 / 27$ & NA \\
\hline & & & & & & & NA & \\
\hline \multirow[t]{2}{*}{ John et $\mathrm{al}^{23}$} & 2006 & China & $\mathrm{HCC}$ & 67 & Santa Cruz & $\mathrm{I}: 500$ & $51 / 16$ & $43 / 14$ \\
\hline & & & & & & & NA & $8 / 2$ \\
\hline \multirow[t]{3}{*}{ King et al ${ }^{17}$} & 2000 & China & $\mathrm{HCC}$ & 58 & Novocastra & $1: 100$ & $28 / 30$ & NA \\
\hline & & & & & Laboratories, Ltd & & & \\
\hline & & & & & & & $5 / 53$ & \\
\hline \multirow[t]{3}{*}{ Harimoto et al ${ }^{18}$} & 2004 & Japan & $\mathrm{HCC}$ & 60 & Novocastra & $\mathrm{I}: 200$ & $26 / 34$ & $19 / 27$ \\
\hline & & & & & Laboratories, Ltd & & & \\
\hline & & & & & & & NA & $7 / 7$ \\
\hline \multirow[t]{2}{*}{ Zhang et al ${ }^{19}$} & 2016 & China & $\mathrm{HCC}$ & 167 & Cell Sigaling & I:I,000 & $81 / 86$ & NA \\
\hline & & & & & Technology & & & \\
\hline \multirow[t]{2}{*}{ Hung et $\mathrm{al}^{25}$} & 2017 & China & $\mathrm{HCC}$ & 80 & Abcam & $\mathrm{I}: 750$ & NA & $53 / 8$ \\
\hline & & & & & & & & $15 / 4$ \\
\hline
\end{tabular}

Note: + means over-expressed and - means lower-expressed.

Abbreviations: AFP, $\alpha$-fetoprotein; DFS, disease-free survival; $\mathrm{HBsAg}$, hepatitis B virus surface antigen; HCC, hepatocellular carcinoma; OS, overall survival; UICC, Union for International Cancer Control; NA, not applicable.

( $\mathrm{OR}=1.96,95 \% \mathrm{CI}=0.91-4.24, P=0.083$; Figure $3 \mathrm{C}$ ), vas- $\quad$ The meta-analysis about the prognostic cular invasion $(\mathrm{OR}=1.71,95 \% \mathrm{CI}=0.93-3.15, P=0.083$; value of $\mathrm{HSP} 27$ in patients with $\mathrm{HCC}$

Figure 4A), and TNM stage ( $\mathrm{OR}=0.66,95 \% \mathrm{CI}=0.27-1.61, \quad$ The relationship between HSP27 expression and the prognosis $P=0.358$; Figure $4 \mathrm{C})$. of patients with HCC was also assessed in this meta-analysis.

Table 2 HSP27 clinicopathological features for HCC

\begin{tabular}{|c|c|c|c|c|c|c|c|}
\hline \multicolumn{8}{|l|}{ Heterogeneity } \\
\hline $\begin{array}{l}\text { Clinicopathological } \\
\text { features }\end{array}$ & $\begin{array}{l}\text { No. of } \\
\text { studies }\end{array}$ & $\begin{array}{l}\text { No. of } \\
\text { patients }\end{array}$ & $\begin{array}{l}\text { Pooled OR } \\
(95 \% \mathrm{Cl})\end{array}$ & PHet & $I^{2}(\%)$ & $P$-value & $\begin{array}{l}\text { Model } \\
\text { used }\end{array}$ \\
\hline Expression & 5 & 237 & $7.00(2.35-20.79)$ & 0.002 & 76.6 & 0.000 & Random \\
\hline Gender & 6 & 478 & I.I3 (0.72-I.77) & 0.142 & 39.5 & 0.606 & Fixed \\
\hline AFP & 3 & 167 & $3.86(1.11-13.39)$ & 0.113 & 54.2 & 0.034 & Random \\
\hline $\mathrm{HBsAg}$ & 6 & 492 & $1.72(0.65-4.52)$ & 0.001 & 74.8 & 0.275 & Random \\
\hline Tumor size & 6 & 304 & $1.19(0.74-1.92)$ & 0.535 & 0.0 & 0.479 & Fixed \\
\hline Metastasis & 6 & 471 & $1.96(0.91-4.24)$ & 0.013 & 65.2 & 0.086 & Random \\
\hline Vascular invasion & 7 & 530 & $1.71(0.93-3.15)$ & 0.037 & 55.2 & 0.083 & Random \\
\hline Differentiation & 9 & 642 & $3.81(1.79-8.08)$ & 0.012 & 59.0 & 0.000 & Random \\
\hline TNM stage & 5 & 444 & $0.68(0.33-1.38)$ & 0.068 & 54.2 & 0.282 & Random \\
\hline
\end{tabular}

Abbreviations: AFP, $\alpha$-fetoprotein; Fixed, fixed-effects model; HCC, hepatocellular carcinoma; OR, odds ratio; Random, random-effects model. 


\begin{tabular}{|c|c|c|c|c|c|c|c|c|}
\hline $\begin{array}{l}\text { AFP } \\
\text { positive }(+I-) \text {, } \\
\text { negative }(+I-)\end{array}$ & $\begin{array}{l}\text { HBsAg } \\
\text { yes }(+I-) \text {, } \\
\text { no }(+I-)\end{array}$ & $\begin{array}{l}\text { Tumor size } \\
\leq 5 \mathrm{~cm}(+I-) \\
>5(+I-)\end{array}$ & $\begin{array}{l}\text { Metastasis, } \\
\text { metastasis }(+I-), \\
\text { Non-metastasis (+l-) }\end{array}$ & $\begin{array}{l}\text { Vascular } \\
\text { invasion } \\
\text { yes }(+I-) \text {, } \\
\text { no }(+l-)\end{array}$ & $\begin{array}{l}\text { Differentiation } \\
\text { low }(+l-) \text {, } \\
\text { high, and } \\
\text { moderate }(+l-)\end{array}$ & $\begin{array}{l}\text { UICC stage } \\
\text { I, II (+I-), } \\
\text { III, IV (+I-) }\end{array}$ & $\begin{array}{l}\text { Survival } \\
\text { information }\end{array}$ & $\begin{array}{l}\text { Quality } \\
\text { score }\end{array}$ \\
\hline $10 / 4$ & $10 / 8$ & $6 / 8$ & NA & NA & $12 / 0$ & $6 / 12$ & NA & 6 \\
\hline $8 / 20$ & $8 / 6$ & $12 / 6$ & & & $6 / 14$ & $12 / 2$ & & \\
\hline \multirow[t]{2}{*}{ NA } & $44 / 9$ & $26 / 7$ & $15 / 4$ & NA & $23 / 2$ & NA & NA & 6 \\
\hline & $7 / 8$ & $25 / 10$ & $29 / 20$ & & $28 / 15$ & & & \\
\hline \multirow[t]{2}{*}{ NA } & NA & $18 / 10$ & $22 / 4$ & $24 / 6$ & $\mathrm{II} / \mathrm{I}$ & NA & NA & 6 \\
\hline & & $12 / 5$ & $8 / 11$ & $6 / 9$ & $19 / 14$ & & & \\
\hline \multirow[t]{2}{*}{ NA } & NA & $6 / 5$ & $15 / 4$ & $12 / 1$ & $15 / 5$ & NA & NA & 6 \\
\hline & & $14 / 9$ & $5 / 10$ & $9 / 13$ & $5 / 9$ & & & \\
\hline \multirow[t]{2}{*}{ NA } & $20 / 11$ & NA & $28 / 5$ I & $7|/ 4|$ & $20 / 10$ & $42 / 34$ & NA & 8 \\
\hline & $98 / 65$ & & $40 / 74$ & $47 / 35$ & $98 / 66$ & $76 / 42$ & & \\
\hline \multirow[t]{2}{*}{ NA } & $40 / 13$ & $16 / 8$ & $12 / 10$ & $16 / 12$ & $36 / 15$ & $12 / 9$ & NA & 8 \\
\hline & $4 / 14$ & $28 / 19$ & $32 / 17$ & $28 / 15$ & $8 / 12$ & $32 / 18$ & & \\
\hline $22 / 1$ & $44 / 14$ & NA & NA & $33 / 8$ & NA & $34 / 8$ & NA & 8 \\
\hline $29 / 15$ & $7 / 2$ & & & $18 / 8$ & & $17 / 8$ & & \\
\hline $18 / 14$ & NA & $16 / 12$ & NA & $20 / 16$ & $17 / 5$ & NA & OS DFS & 7 \\
\hline $12 / 14$ & & $12 / 18$ & & $8 / 14$ & $11 / 25$ & & & \\
\hline \multirow[t]{2}{*}{ NA } & $10 / 20$ & NA & $6 / 6$ & $9 / 14$ & $8 / 13$ & NA & OS DFS & 8 \\
\hline & $16 / 14$ & & $20 / 28$ & $17 / 20$ & $|8 / 2|$ & & & \\
\hline NA & NA & NA & NA & NA & NA & NA & OS DFS & 9 \\
\hline \multirow[t]{2}{*}{ NA } & NA & NA & NA & NA & $19 / 0$ & $39 / 8$ & OS & 8 \\
\hline & & & & & $49 / 12$ & $29 / 4$ & & \\
\hline
\end{tabular}

The HRs for the overall survival rate were examined in 4 studies (Harimoto et al had 2 sets of data), which included 203 and 162 HCC patients with and without HSP27 expression, respectively. Our evaluation of the data revealed that HSP27 expression was associated with poor overall survival (positive: negative: $\mathrm{HR}=1.13,95 \% \mathrm{CI}=1.39-2.53, P=0.000$; Figure 5A). Additionally, we examined the HRs for diseasefree survival rate in 3 studies (Harimoto et al had 2 sets of data), which included 135 and 150 HCC patients with and without HSP27 expression, respectively. The meta-analysis showed that HSP27 expression was not associated with disease-free survival (positive: negative: $\mathrm{HR}=1.54,95 \%$ $\mathrm{CI}=0.93-2.14, P=0.673$; Figure 5B)

\section{Publication bias and sensitivity analysis}

No publication bias was found for HSP27 expression ( $P=0.086)$, gender $(P=0.133)$, AFP $(P=0.296)$, tumor size $(P=1)$, metastasis $(P=0.133)$, HBsAg $(P=0.452)$, tumor differentiation $(P=0.118)$, TNM stage $(P=0.806)$, overall survival rate $(P=0.308)$, and disease-free survival rate $(P=0.734)$ according to the Begg's test. However, publication bias existed for vascular invasion $(P=0.035)$ and the sensitivity analysis was calculated to determine whether individual studies influenced the pooled OR. The result indicated that no study substantially influenced the pooled OR, which suggested that more studies needed to be included for further research.

\section{Discussion}

HSPs are widely found in prokaryotic and eukaryotic cells. They comprise various groups of conserved proteins that have important physiological functions and play key roles in cell growth, differentiation, and gene transcription. ${ }^{26}$ In recent years, studies have found that HSPs are involved in the development of tumors. ${ }^{27}$ HSP27 is a member of the HSP family, which acts as an ATPaseindependent chaperone. Several studies suggest that HSP27 is involved in the regulation of cell cycle, inhibition of cell 
A
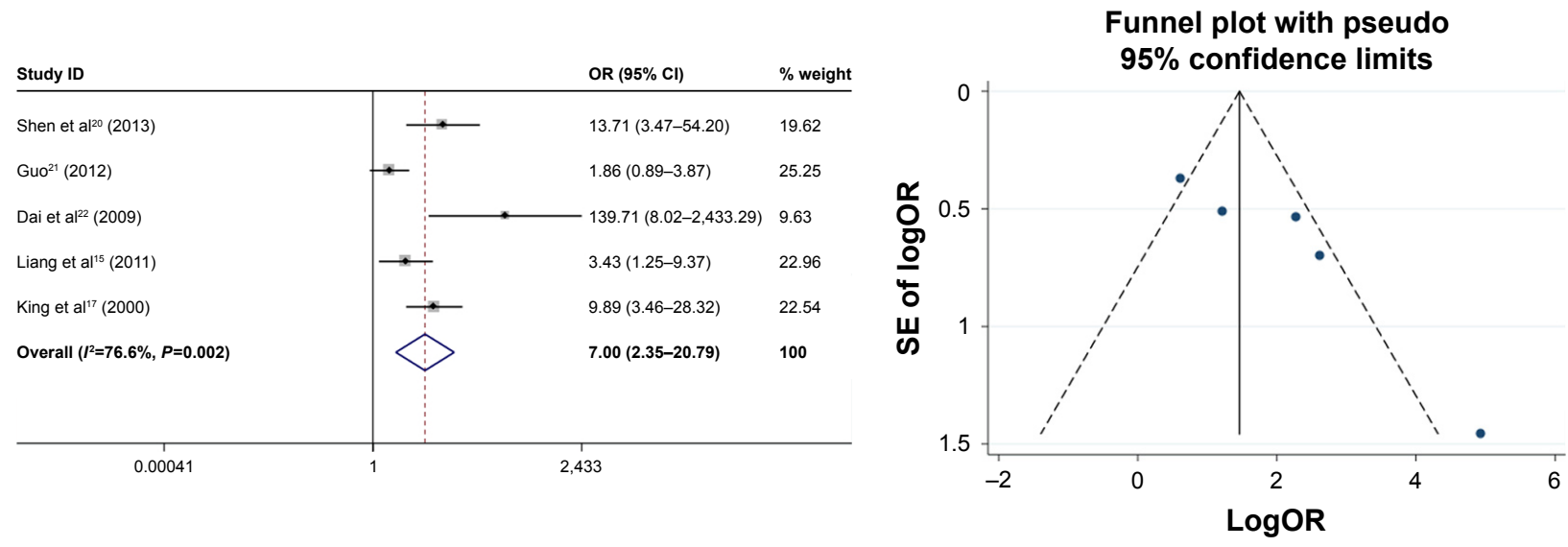

B
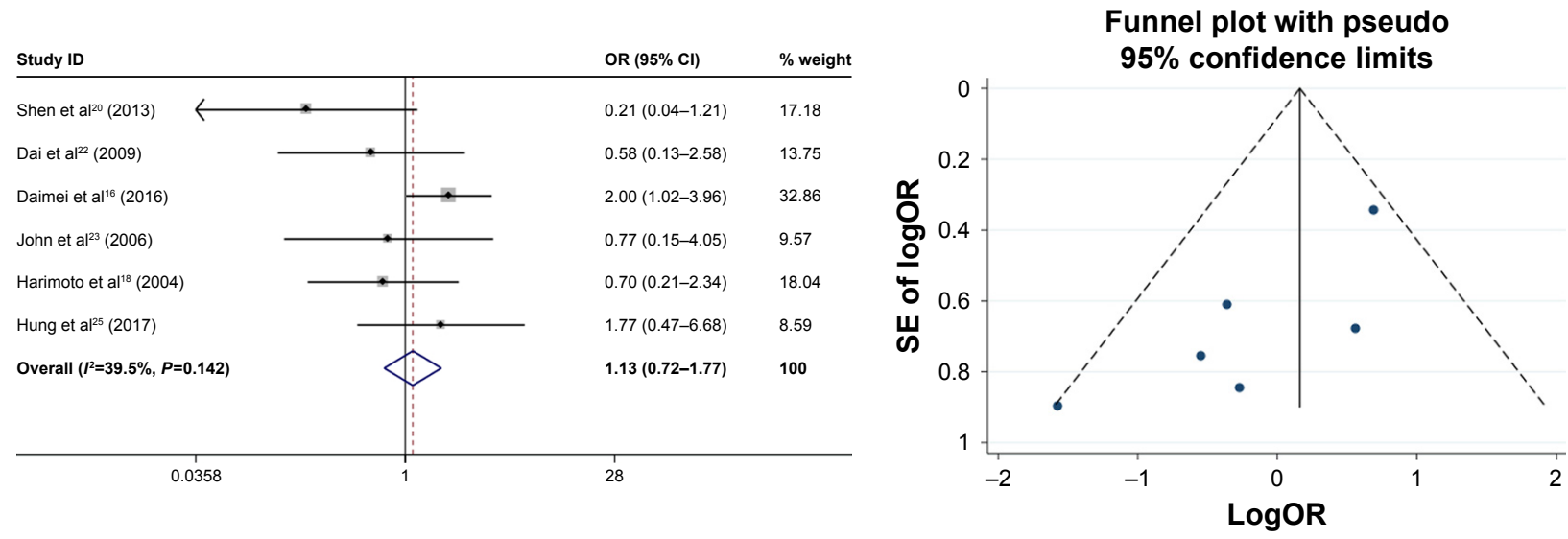

C
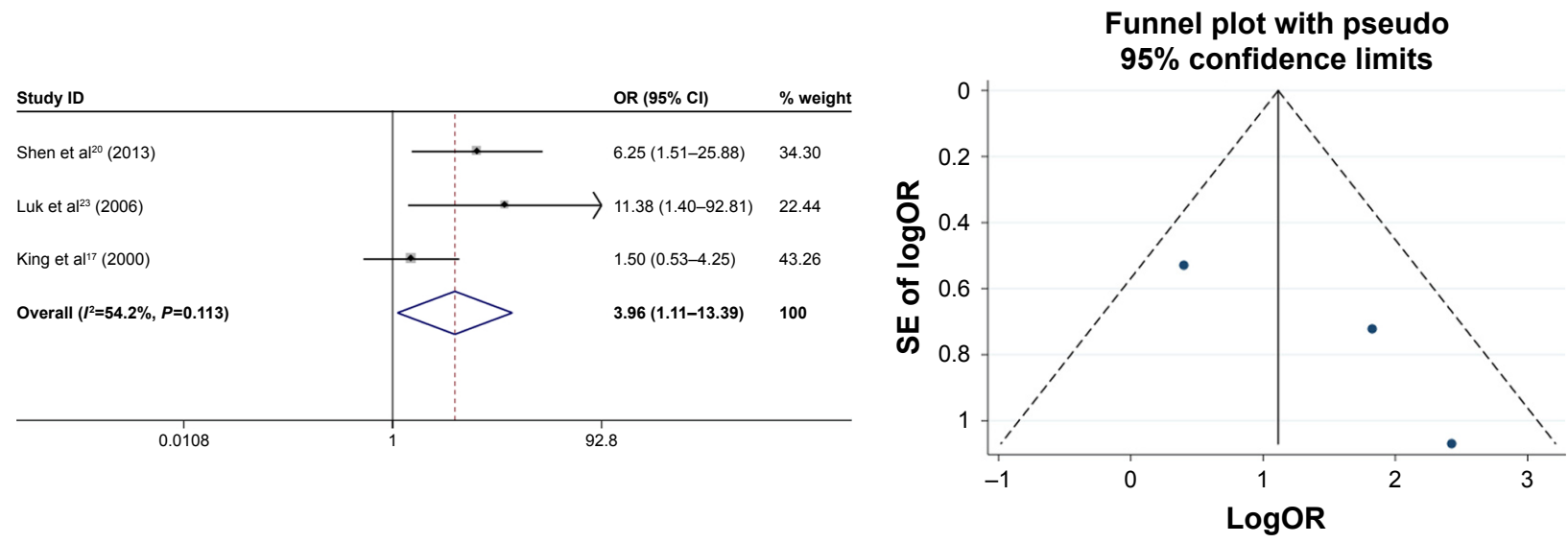

Figure 2 Forest plot and funnel plots of studies evaluating the relationship between HSP27 expression and clinicopathological features. Notes: (A) Expression; (B) gender; (C) AFP level. Weights are from random effects analysis.

Abbreviations: AFP, $\alpha$-fetoprotein; OR, odds ratio.

apoptosis, remodeling of skeletal structures, regulation of translation initiation, DNA repair, RNA cleavage, and ubiquitin-proteasome pathway degradation of oxidized proteins. ${ }^{28}$ Additionally, it has been reported that Hsp27 can promote the metastasis ability of tumors through a variety of different molecular mechanisms. For instance, the mitogen-activated protein kinase kinase 4-mediated enhancement of cell invasion is mainly dependent on the role of Hsp27 and MMP2 $2{ }^{29}$ Moreover, Hsp27 maintains the stem cell characteristics of breast cancer stem cells by upregulating cell epithelial-mesenchymal transition (EMT) and the nuclear factor-kappa-B signaling pathway. ${ }^{30}$ HSP27 also plays an extremely important role in epidermal growth factor-, hepatocyte growth factor-, and interleukin-6mediated EMT progression in prostate cancer. ${ }^{11}$ HSP27 has also been suggested to promote tumor metastasis through the regulation of the transforming growth factor beta signaling pathway by activating the expression of MMP2. ${ }^{31} \mathrm{HSP} 27$ can 
A
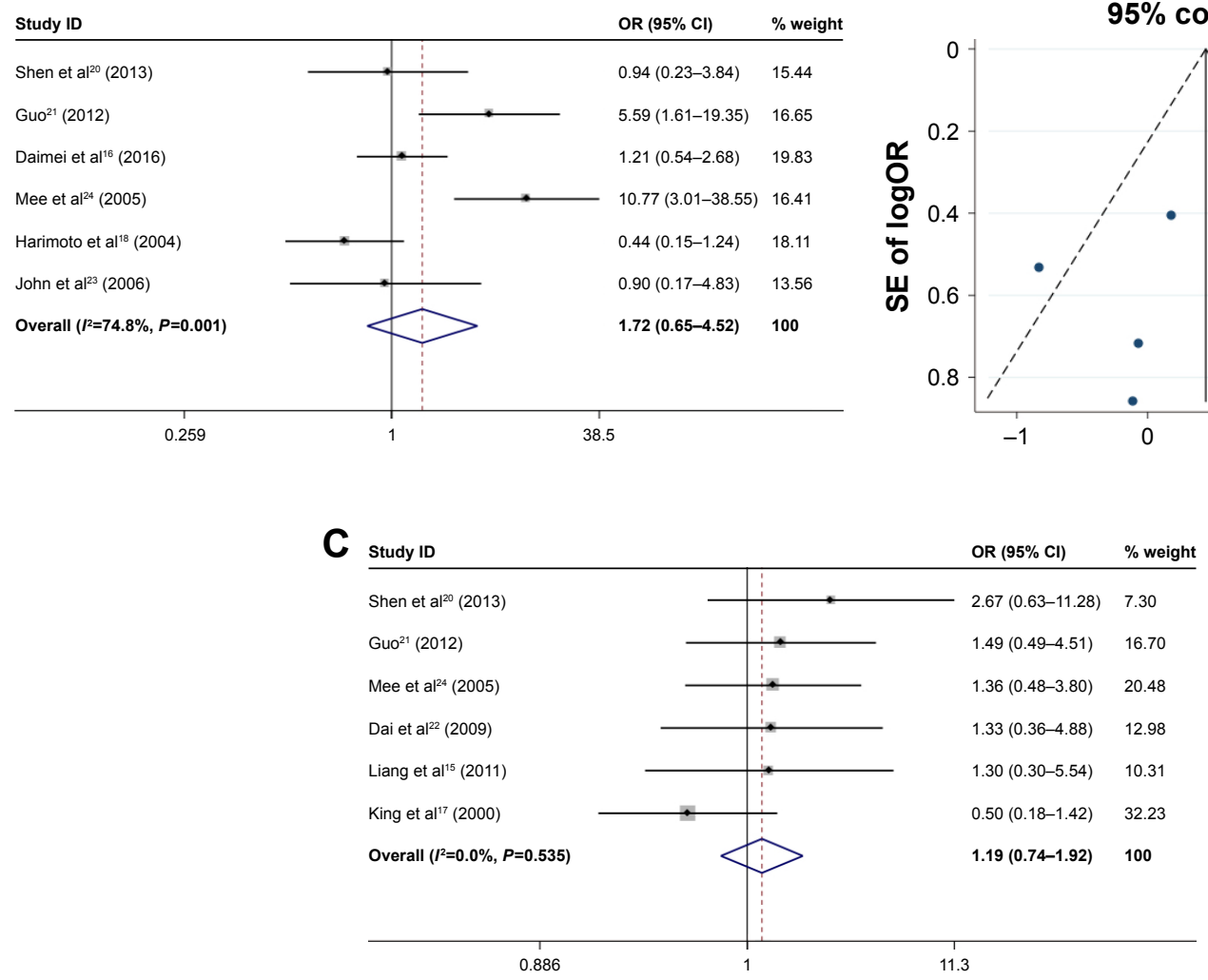

B Funnel plot with pseudo

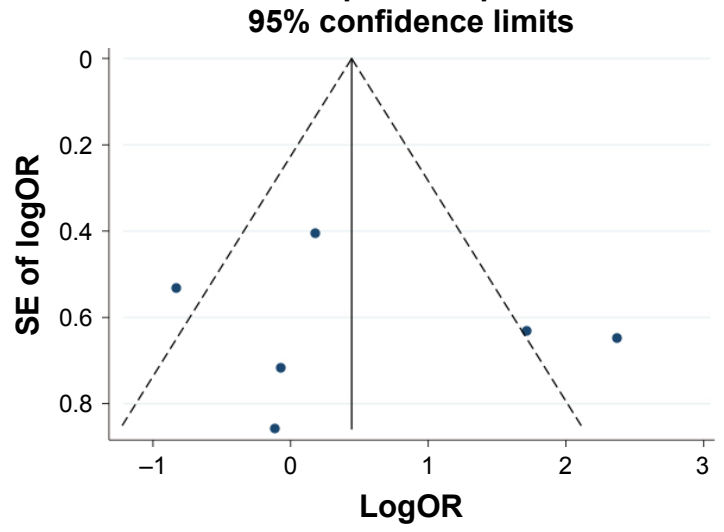

Figure 3 Forest plot and funnel plots of studies evaluating the relationship between HSP27 expression and clinicopathological features. Notes: (A) HBsAg; (B) tumor size; (C) metastasis. Weights are from random effects analysis. Abbreviation: OR, odds ratio.

act as a chaperone and perform different cellular functions due to its specific interaction with different binding proteins. For example, HSP27 interacts with tumor protein, translationallycontrolled 1 (TPT1, also known as TCTP) and stabilizes the structure of TPT1, which, in turn, reduces the expression and activity of p53. ${ }^{32}$ HSP2 2 also plays a role in inhibiting apoptosis by interacting with cytochrome-c and caspase- $3 .^{33,34}$ HSP27 directly interacts with AKT to increase its stability, which, in turn, leads to increased level of phosphorylation of p21, both of which are essential survival factors in DNAdamaged cells induced by ultraviolet radiation. ${ }^{35}$ HSP27 interacts with insulin-like growth factor 1 and stabilizes the structure of the $\mathrm{Bad} / 14-3-3$ complex, allowing Bad to stay in the cytoplasm and preventing its translocation to the nuclei, thus promoting cell survival. ${ }^{36} \mathrm{~A}$ recent report also suggested that HSP27 can also downregulate the hippo tumor suppressor pathway. ${ }^{37}$ In addition, some studies have also shown that HSP27 can directly interact with 14-3-3 to promote the progression of non-small cell lung cancer. ${ }^{38}$ Indeed, inhibition of HSP27 by small interfering RNA (siRNA) or antisense oligonucleotide significantly was found to increase the therapeutic effect of radiotherapy, paclitaxel, HSP90 inhibitor, MET kinase inhibitor, and gemcitabine ${ }^{39-42}$ In summary, HSP27 could become one of the molecular target of drugs for the treatment of tumors.

Recently, multiple studies demonstrated that HSP27 was highly expressed in a variety of cancers, and its expression was associated with the clinicopathological features and prognosis of the patients with these cancers. ${ }^{14,43}$ However, since the role of HSP27 in HCC remains controversial, we conducted this meta-analysis to clarify the association between HSP27 expression and clinicopathological features and prognosis in patients with HCC. The results of this meta-analysis, which included 876 patients from 11 studies, indicated that HSP27 was overexpressed in HCC patients and HSP27 expression is significantly related to AFP level, and tumor differentiation in HCC patients. Moreover, we also found that the positive expression of HSP27 predicted a poor overall survival rate, suggesting that HSP27 may be a reliable prognostic biomarker in HCC patients.

In this study, 2 of the articles included, namely Guo et a $1^{21}$ and Joo et al, ${ }^{24}$ suggested that HSP27 expression was related to the HBsAg. Additionally, $2^{15,22}$ of $6,2^{22}$ of 7 , and $1^{20}$ of 5 studies indicated that overexpression of HSP27 correlated 
A

\begin{tabular}{|c|c|c|}
\hline Study ID & OR $(95 \% \mathrm{CI})$ & $\%$ weight \\
\hline Dai et al22 (2009) & $6.00(1.53-23.53)$ & 11.59 \\
\hline Daimei et al ${ }^{16}(2016)$ & $1.29(0.72-2.31)$ & 22.21 \\
\hline Mee et $\mathrm{al}^{24}(2005)$ & $0.71(0.27-1.90)$ & 16.23 \\
\hline John et $\mathrm{al}^{23}(2006)$ & $1.83(0.59-5.71)$ & 14.14 \\
\hline Liang et $\mathrm{al}^{15}(2011)$ & $17.33(1.90-158.00)$ & 5.96 \\
\hline King et al ${ }^{17}(2000)$ & $2.19(0.74-6.50)$ & 14.73 \\
\hline Harimoto et al ${ }^{18}(2004)$ & $0.76(0.26-2.18)$ & 15.13 \\
\hline Overall $\left(I^{2}=55.2 \%, P=0.037\right)$ & $1.71(0.93-3.15)$ & 100 \\
\hline
\end{tabular}

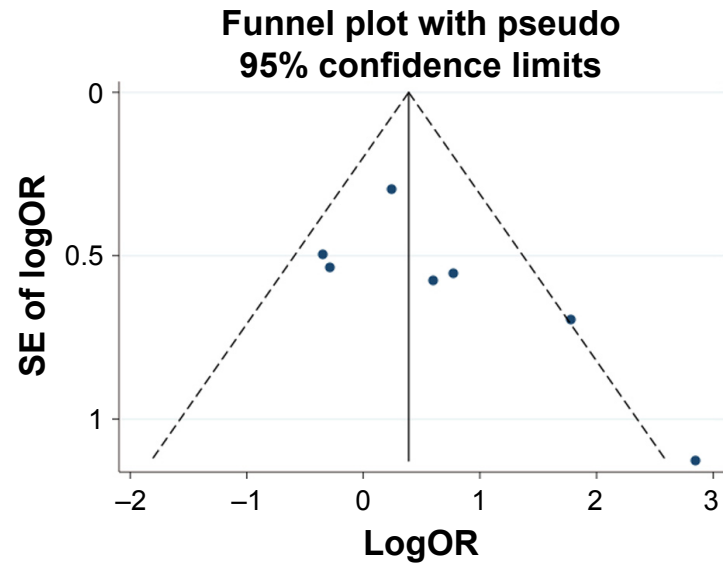

B

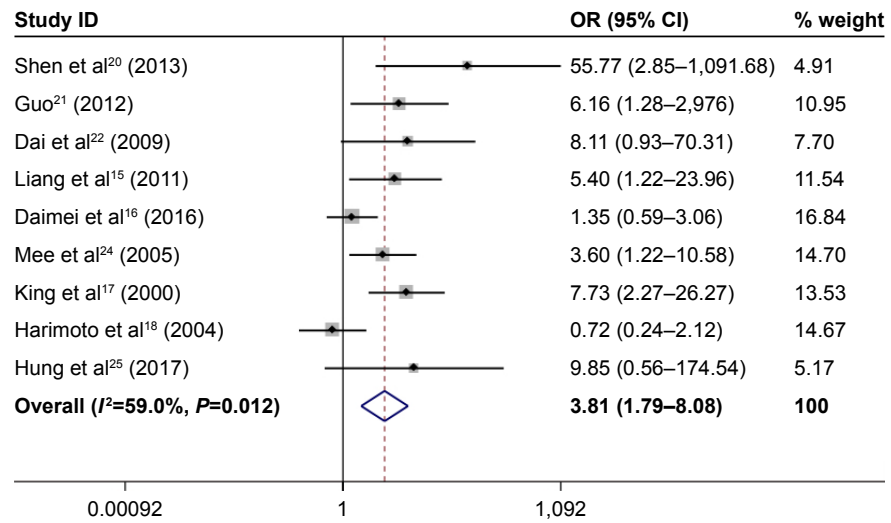

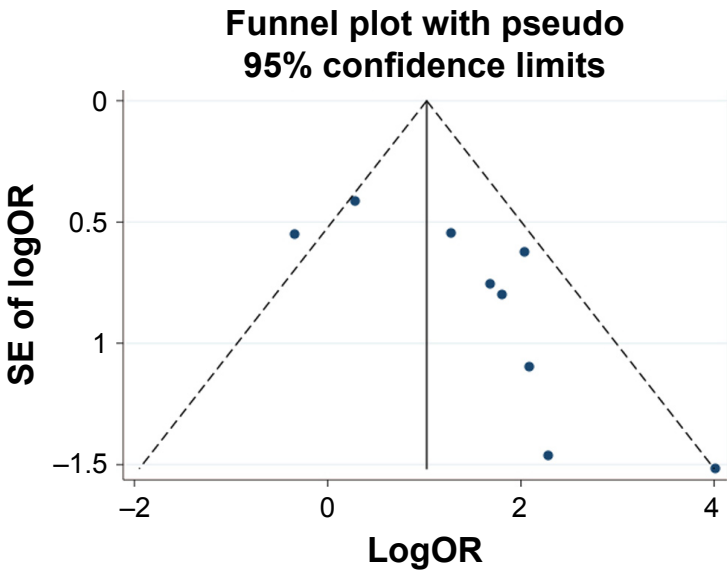

C

\begin{tabular}{|c|c|c|}
\hline Study ID & OR $(95 \% \mathrm{Cl})$ & $\%$ weight \\
\hline Shen et $\mathrm{al}^{20}(2013)$ & $0.06(0.01-0.50)$ & 11.28 \\
\hline Daimei et al ${ }^{16}(2016)$ & $0.68(0.38-1.23)$ & 30.79 \\
\hline Mee et $\mathrm{al}^{24}(2005)$ & $0.75(0.27-2.12)$ & 21.32 \\
\hline John et $\mathrm{al}^{23}(2006)$ & $2.00(0.64-6.25)$ & 19.53 \\
\hline Hung et $\mathrm{al}^{25}(2017)$ & $0.67(0.18-2.45)$ & 17.08 \\
\hline Overall $\left(I^{2}=54.2 \%, P=0.068\right)$ & $0.68(0.33-1.38)$ & 100 \\
\hline
\end{tabular}

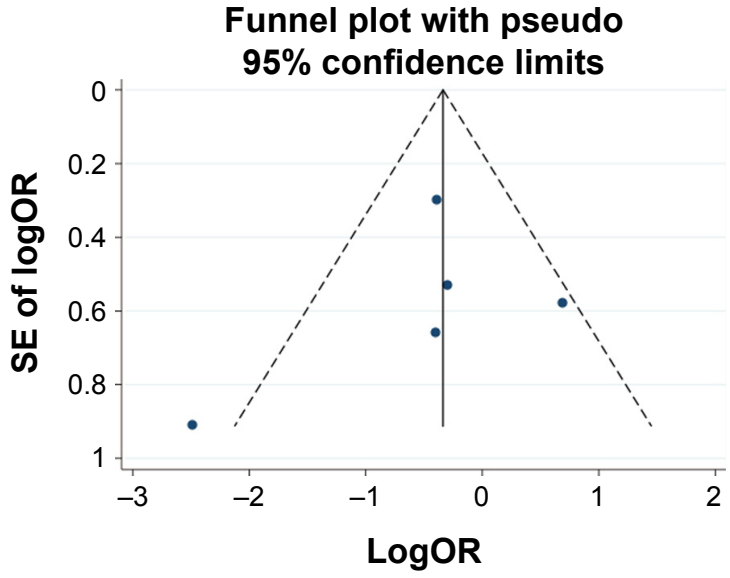

Figure 4 Forest plot and funnel plots of studies evaluating the relationship between HSP27 expression and clinicopathological features.

Notes: (A) Vascular invasion; (B) tumor differentiation; (C) TNM stage. Weights are from random effects analysis.

Abbreviation: OR, odds ratio.

with metastasis, vascular invasion, and TNM stage. However, the pooled results showed no statistically significant relationship between HSP27 and these clinicopathological features. Also, although King et $\mathrm{al}^{17}$ and Zhang et al ${ }^{19}$ suggested that expression of HSP27 indicated a poor diseasefree survival, the results of this meta-analysis showed no statistical significance.
Recently, studies demonstrated that phosphorylated HSP27 may also play an important role in cancers. It has been reported that p-HSP27 was associated with the tumor diameter and portal vein invasion in $\mathrm{HCC} .{ }^{16}$ Moreover, p-HSP27 was related to EMT, apoptosis resistance. ${ }^{44,45}$ However, p-HSP27 may play a different role from HSP27. Studies found that reduced p-HSP27 was associated with 
A
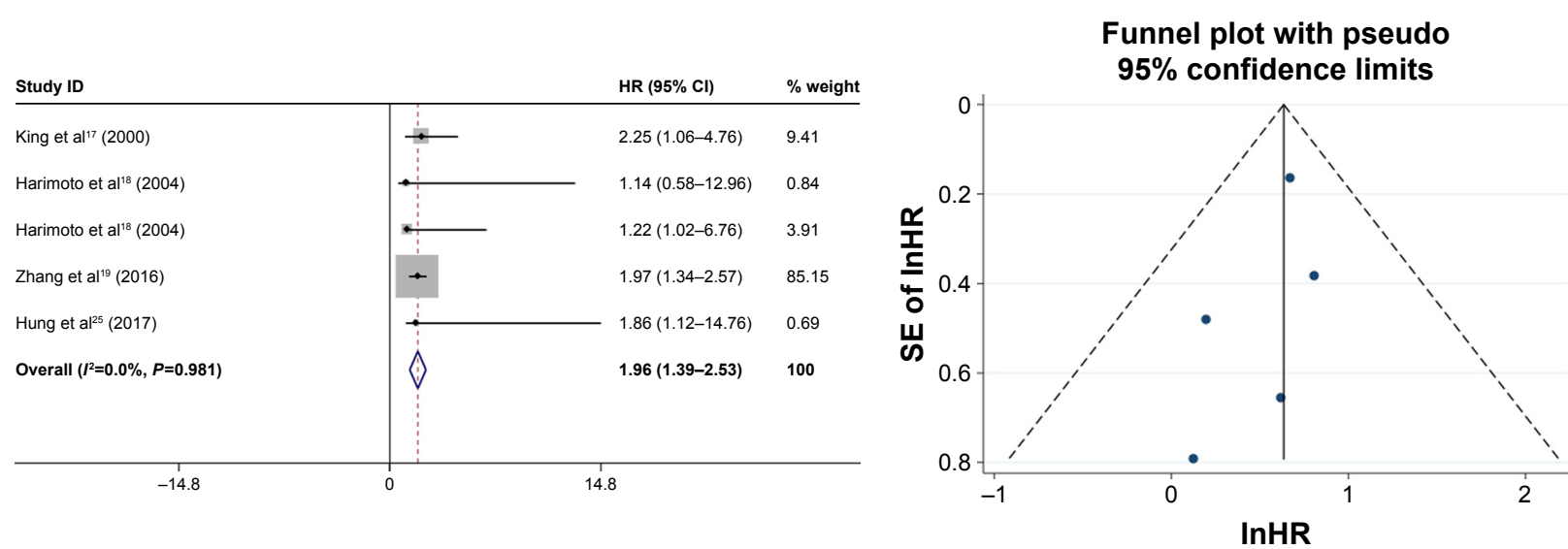

B
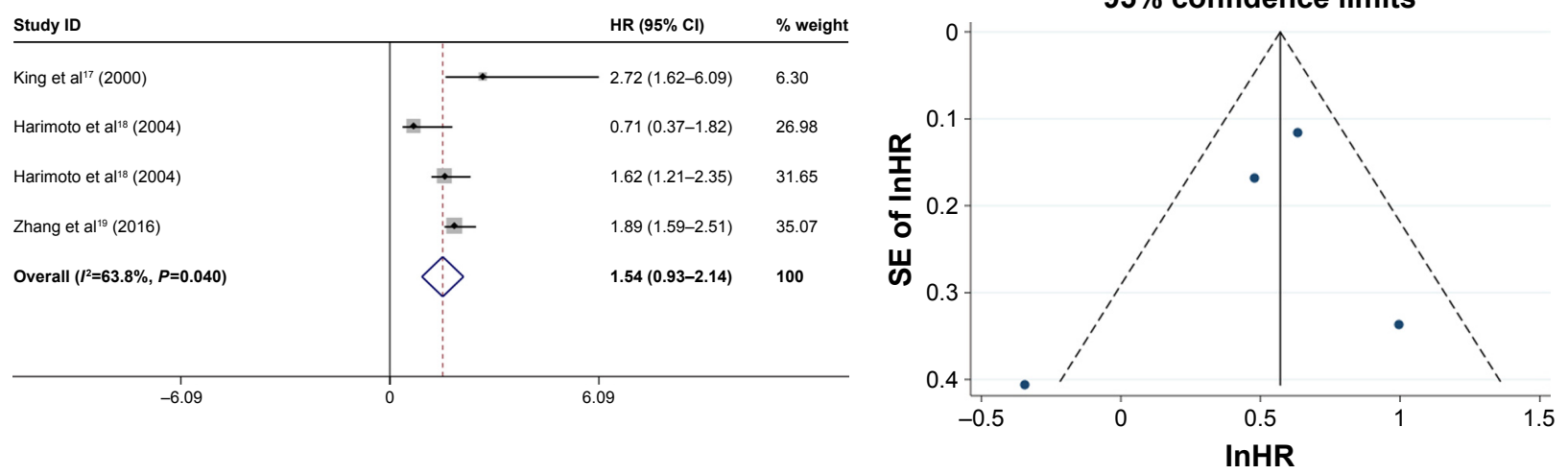

Figure 5 Forest plot and funnel plots of studies evaluating the relationship between HSP27 expression and prognosis of HCC patients. Notes: (A) Overall survival; (B) disease-free survival. Weights are from random effects analysis. Abbreviations: HCC, hepatocellular carcinoma; HR, hazard ratio.

HCC stage, ${ }^{46}$ so further research should be performed to explore the various function of HSP27.

\section{Limitations}

This meta-analysis has some limitations, including the following: 1) There may be some articles with controversial results that have not been published, which may have led to publication bias. 2) With regard to the experimental method, we only chose studies that used IHC analysis in this study. When we carefully read the contents of the articles, we found that the antibody manufacturer and antibody concentration used in the experiments were not the same, and the cut-off values for HSP27 expression differed among the articles. These differences are likely to affect the final result and cause bias, thus more studies with similar antibody, concentration of antibody, and cut-off criteria are needed in order to verify the results of this meta-analysis. 3) Studies included in this meta-analysis only comprised patients of Asian race, including Chinese, South Korean, and Japanese. Accordingly, these results may only be suitable for Asian races, and thus more studies from other areas are needed. 4) Some articles did not provide specific HRs value, which we extracted by software and may cause bias. 5) The number of studies and sample size included in this meta-analysis are limited. Thus, larger samples and additional high-quality studies are needed to confirm the results of this meta-analysis.

\section{Conclusion}

Despite the limitations in this meta-analysis, the results are significant. The pooled results indicated that HSP27 expression was related to the incidence of HCC, AFP level, and tumor differentiation. Additionally, HSP27 may be a biomarker of unfavorable prognosis of patients with HCC. However, more high-quality studies are needed to achieve a more convincing statistical analysis.

\section{Acknowledgments}

This study was financially supported by the Beijing Municipal Administration of Hospital Clinical Medicine Development of Special Funding Support (ZYLX201612), Capital Foundation of Medical Development (shoufa2016-2-2053), Beijing Tongren Hospital Municipal Administration of Hospital 
Clinical Medicine Development of Special Funding Support (trzdyxzy201705).

\section{Disclosure}

The authors report no conflicts of interest in this work.

\section{References}

1. Marquardt JU, Thorgeirsson SS. SnapShot: Hepatocellular carcinoma. Cancer Cell. 2014;25(4):550.e1.

2. Siegel R, Naishadham D, Jemal A. Cancer statistics, 2012. CA Cancer J Clin. 2012;62(1):10-29.

3. Forner A, Llovet JM, Bruix J. Hepatocellular carcinoma. Lancet. 2012;379(9822):1245-1255.

4. Avila MA, Berasain C, Sangro B, Prieto J. New therapies for hepatocellular carcinoma. Oncogene. 2006;25(27):3866-3884.

5. Gomez-Pastor R, Burchfiel ET, Thiele DJ. Regulation of heat shock transcription factors and their roles in physiology and disease. Nat Rev Mol Cell Biol. 2018;19(1):4-19.

6. Wang C, Zhang Y, Guo K, et al. Heat shock proteins in hepatocellular carcinoma: molecular mechanism and therapeutic potential. Int $J$ Cancer. 2016;138(8):1824-1834.

7. Wu J, Liu T, Rios Z, Mei Q, Lin X, Cao S. Heat shock proteins and cancer. Trends Pharmacol Sci. 2017;38:226-256.

8. Luz CC, Noguti J, Borges de Araujo L, Gianni MS, Simao Gomes T, Ricardo AN. Hsp27 and Hsp70 expression in Esophageal Squamous. Asian Pac J Cancer Prev. 2017;18(3):789-794.

9. Giaginis C, Daskalopoulou SS, Vgenopoulou S, Sfiniadakis I, Kouraklis G, Theocharis SE. Heat Shock Protein-27, -60 and -90 expression in gastric cancer: association with clinicopathological variables and patient survival. BMC Gastroenterol. 2009;9:14.

10. Yu Z, Zhi J, Peng X, Zhong X, Xu A. Clinical significance of HSP27 expression in colorectal cancer. Mol Med Rep. 2010;3(6):953-958.

11. Cordonnier T, Bishop JL, Shiota M, et al. Hsp27 regulates EGF/betacatenin mediated epithelial to mesenchymal transition in prostate cancer. Int $J$ Cancer. 2015;136(6):E496-E507.

12. Ioachim E, Tsanou E, Briasoulis E, et al. Clinicopathological study of the expression of hsp27, pS2, cathepsin D and metallothionein in primary invasive breast cancer. Breast. 2003;12(2):111-119.

13. Malusecka E, Zborek A, Krzyzowska-Gruca S, Krawczyk Z. Expression of heat shock proteins HSP70 and HSP27 in primary non-small cell lung carcinomas. An immunohistochemical study. Anticancer Res. 2001;21(2A):1015-1021.

14. Li S, Zhang W, Fan J, Lai Y, Che G. Clinicopathological and prognostic significance of heat shock protein 27 (HSP27) expression in non-small cell lung cancer: a systematic review and meta-analysis. Springerplus. 2016;5(1):1165.

15. LiangDQ, Xiaoping L, LinglingZ, Xinghuo T. 肝癌组织中Cyr61、VEGF 和HSP27的表达和临床意义 [Expression and their clinical significance of Cyr61, VEGF and HSP27 in hepatocellular carcinoma]. Shandong Med J. 2011;51:19-21. Chinese.

16. Daimei Eto, Hisaka T, Horiuchi H, et al. Expression of HSP27 in Hepatocellular Carcinoma. Anticancer Res. 2016;36(7):3775-3779.

17. King KL, Li AF, Chau GY, et al. Prognostic significance of heat shock protein-27 expression in hepatocellular carcinoma and its relation to histologic grading and survival. Cancer. 2000;88(11):2464-2470.

18. Harimoto N, Shimada M, Aishima S, et al. The role of heat shock protein 27 expression in hepatocellular carcinoma in Japan: special reference to the difference between hepatitis B and C. Liver Int. 2004;24(4):316-321.

19. Zhang Y, Tao X, Jin G, et al. A targetable molecular chaperone Hsp27 confers aggressiveness in hepatocellular carcinoma. Theranostics. 2016;6(4):558-570.

20. Shen D, LiLi, Jian G. 热休克蛋白-27 与磷脂酰肌醇蛋白聚糖-3 在原 发性肝癌中的表达及意义 [Expression of HSP27 and GPC-3 in primary hepatic cancer and its clinical implication]. Chongqing Med J. 2013; 1(4):593-598. Chinese.
21. Guo W. Expression of HSP27 and VEGF in HCC and its Clinical Implication. [master's thesis]. Guilin Medical University of China; 2012.

22. Dai FJ, MaoHui F, Wei X, et al. HSP27在肝癌中的表达及临床意义 [Expression of HSP27 in hepatocellular carcinoma (HCC) and its clinical implication]. Chin Cancer Clin. 2009;2:578-581. Chinese.

23. Luk JM, Lam CT, Siu AF, et al. Proteomic profiling of hepatocellular carcinoma in Chinese cohort reveals heat-shock proteins (Hsp27, Hsp70, GRP78) up-regulation and their associated prognostic values. Proteomics. 2006;6(3):1049-1057.

24. Mee JOO, Chi JG, Lee H. Expressions of HSP70 and HSP27 in hepatocellular carcinoma. J Korean Med Sci. 2005;20(5):829-834.

25. Hung CS, Huang CY, Lee $\mathrm{CH}$, et al. IGFBP2 plays an important role in heat shock protein 27-mediated cancer progression and metastasis. Oncotarget. 2017;8(33):54978-54992.

26. Jolly C, Morimoto RI. Role of the heat shock response and molecular chaperones in oncogenesis and cell death. J Natl Cancer Inst. 2000; 92(1):1564-1572.

27. Khalil AA, Kabapy NF, Deraz SF, Smith C. Heat shock proteins in oncology: diagnostic biomarkers or therapeutic targets? Biochim Biophys Acta. 2011;1816(2):89-104.

28. Cheng J, Lv Z, Weng X, et al. Hsp27 acts as a master molecular chaperone and plays an essential role in hepatocellular carcinoma progression. Digestion. 2015;92(4):192-202.

29. Pavese JM, Ogden IM, Voll EA, et al. Mitogen-activated protein kinase kinase 4 (MAP2K4) promotes human prostate cancer metastasis. PLoS One. 2014;9(7):e102289.

30. Wei L, Liu TT, Wang HH, et al. Hsp27 participates in the maintenance of breast cancer stem cells through regulation of epithelial-mesenchymal transition and nuclear factor-kappaB. Breast Cancer Res. 2011;13(5):R101.

31. Xu L, Chen S, Bergan RC. MAPKAPK2 and HSP27 are downstream effectors of p38 MAP kinase-mediated matrix metalloproteinase type 2 activation and cell invasion in human prostate cancer. Oncogene. 2006; 25(21):2987-2998

32. Baylot V, Katsogiannou M, Andrieu C, et al. Targeting TCTP as a new therapeutic strategy in castration-resistant prostate cancer. Mol Ther. 2012;20(12):2244-2256.

33. Bruey JM, Ducasse C, Bonniaud P, et al. Hsp27 negatively regulates cell death by interacting with cytochrome c. Nat Cell Bio. 2000;2(1): 645-652.

34. Pandey P, Farber R, Nakazawa A, et al. Hsp27 functions as a negative regulator of cytochrome c-dependent activation of procaspase-3. Oncogene. 2000;19:1975-1981.

35. Kanagasabai R, Karthikeyan K, Vedam K, Qien W, Zhu Q, Ilangovan G. Hsp27 protects adenocarcinoma cells from UV-induced apoptosis by Akt and p21-dependent pathways of survival. Mol Cancer Res. 2010;8(10):1399-1412.

36. Zoubeidi A, Zardan A, Wiedmann RM, et al. Hsp27 promotes insulinlike growth factor-I survival signaling in prostate cancer via p90Rskdependent phosphorylation and inactivation of BAD. Cancer Res. 2010; 70(6):2307-2317.

37. Vahid S, Thaper D, Gibson KF, Bishop JL, Zoubeidi A. Molecular chaperone Hsp27 regulates the Hippo tumor suppressor pathway in cancer. Sci Rep. 2016;6:31842.

38. Zhao GY, Ding JY, Lu CL, Lin ZW, Guo J. The overexpression of 14-3-3zeta and Hsp27 promotes non-small cell lung cancer progression. Cancer. 2014;120(5):652-663.

39. Hadchity E, Aloy MT, Paulin C, et al. Heat shock protein 27 as a new therapeutic target for radiation sensitization of head and neck squamous cell carcinoma. Mol Ther. 2009;17(8):1387-1394.

40. Kamada M, So A, Muramaki M, Rocchi P, Beraldi E, Gleave M. Hsp27 knockdown using nucleotide-based therapies inhibit tumor growth and enhance chemotherapy in human bladder cancer cells. Mol Cancer Ther. 2007;6(1):299-308.

41. Lamoureux F, Thomas C, Yin MJ, Fazli L, Zoubeidi A, Gleave ME. Suppression of heat shock protein 27 using OGX-427 induces endoplasmic reticulum stress and potentiates heat shock protein 90 inhibitors to delay castrate-resistant prostate cancer. Eur Urol. 2014;66(1):145-155. 
42. Musiani D, Konda JD, Pavan S, et al. Heat-shock protein 27 (HSP27, HSPB1) is up-regulated by MET kinase inhibitors and confers resistance to MET-targeted therapy. FASEB J. 2014;28(9):4055-4067.

43. Ge H, He X, Guo L, Yang X. Clinicopathological significance of HSP27 in gastric cancer: a meta-analysis. OncoTargets Ther. 2017;10: 4543-4551.

44. Xu Y, Diao Y, Qi S, et al. Phosphorylated Hsp27 activates ATMdependent $\mathrm{p} 53$ signaling and mediates the resistance of MCF-7 cells to doxorubicin-induced apoptosis. Cell Signal. 2013;25(5):1176-1185.
45. Wang HQ, Yang B, Xu CL, et al. Differential phosphoprotein levels and pathway analysis identify the transition mechanism of LNCaP cells into androgen-independent cells. Prostate. 2010;70(5):508-517.

46. Yasuda E, Kumada T, Takai S, et al. Attenuated phosphorylation of heat shock protein 27 correlates with tumor progression in patients with hepatocellular carcinoma. Biochem Biophys Res Commun. 2005;337(1):337-342.

\section{Publish your work in this journal}

OncoTargets and Therapy is an international, peer-reviewed, open access journal focusing on the pathological basis of all cancers, potential targets for therapy and treatment protocols employed to improve the management of cancer patients. The journal also focuses on the impact of management programs and new therapeutic agents and protocols on

\section{Dovepress}

patient perspectives such as quality of life, adherence and satisfaction. The manuscript management system is completely online and includes a very quick and fair peer-review system, which is all easy to use. Visit http://www.dovepress.com/testimonials.php to read real quotes from published authors.

Submit your manuscript here: http://www.dovepress.com/oncotargets-and-therapy-journal 